\title{
Ageing with a Captive Society in London: Audrey, Ron and
}

Smokey at the Zoo.

Adam Reed

University of St Andrews, St Andrews, UK

\section{Abstract:}

This paper considers the spatio-temporal capacity of a set of relationships as they are identified by a group of older people who are regular visitors to London Zoo. It explores the intersections between the time of retirement and the scales and directionality of time commonly invoked by zoological forms of knowledge about species and biodiversity. This includes a look at how both positive and negative theories of futures, including the future of the zoo itself, become a prism through which individuals examine their relationships to time towards the end of life. In addition, the paper focuses on those visitors who seek, in a hopeful manner, to reorient themselves in the city through engagements with individual captive animals.

Keywords: zoo, city, inter-species encounter, extinction

\section{Introduction:}

Its mid July and I am standing looking at a group of black haired monkeys as they scamper and swing about their enclosure, back and forth between the glass- 
fronted interior and the outside caged space. Like the other zoo visitors present, my attention is increasingly drawn to one particular pink squashed face, which seems to be intently watching us. 'That's Smokey, a fourteen year old male,' a voice close behind me explains. I turn around, 'and I'm Ron.' The stranger, obviously dressed for the warmer weather in a nylon sleeveless jacket, shorts, safari-style sun hat, socks and sandals, greets me with a ruddy-faced smile. Gazing back through his thick-rimmed glasses, the man adds, 'I think he's taken a shine to you.' Indeed, when I look back to the enclosure it does appear that I am being singled out. Smokey stares in my direction; each time I move, he follows, at moments coming forward to gesticulate and dance about. Ron laughs. Bending forward, he puckers his lips to utter an imitation primate call and then quite abruptly departs.

This fleeting encounter was my first meeting with one of the small group of retired white working class Londoners who self-identified as regular callers at the Regent's Park zoo. For these older men and women, part of the attraction of the zoological garden lay in the practical fact that it was an affordable destination; since all Londoners over sixty are entitled to free travel on public transport and with an annual zoo pass the daily cost of entry is only a matter of pence. This allowed them to remain at the zoo for long hours; Ron, for instance, told me that he came three to four days a week, leaving his flat in Edgware, a suburb of North London, to take a bus to Camden Town and then walk along the towpath of the Regent's Canal until he reached the zoo entrance. However, the main attraction was always the captive animals themselves. My meetings with these regular visitors were nearly always mediated by the encounter we had together with groups or individual captive creatures such as Smokey. But while 
the older men and women enjoyed sharing with me their enthusiasm for and knowledge of particular zoo animals, individuals also stressed that they liked to keep to themselves. So, for them another part of the draw of the zoological garden lay in the fact it was an outdoor location in London where they could safely go alone; of the fifteen or so regulars that I identified (fieldwork conducted between 1999 and 2000), most were either widowed or, like Ron, single. Although they certainly knew of each other, and sometimes stopped to chat, their visits were usually solitary affairs. London Zoo then was also a place to be around others without necessarily feeling compelled to keep human company.

Indeed, as I came to discover, the zoological gardens and the encounters with its animals sometimes offered these regular visitors a relief from what felt like too-human-filled metropolitan life. Ron spoke of his visits providing him with a 'certain serenity' that he struggled to find outside in the city. Others highlighted the zoo as a site for critical reflection on their own emplacement in London. Such themes have a long genealogy in the history of metropolitan zoos. Initially conceived as a site where wild and exotic creatures might be tamed and civilised — a process taken to duplicate the subjugation of colonized peoples, but in addition the positive, elevated effects of urbanization_— by the twentieth century zoos were being celebrated as locations of urban escape into Nature or the Wild (Cf. Mullan \& Marvin 1987, Baratay \& Hardouin-Fugie 2002, Rothfels 2008). Embodied first in the practice of aristocratic promenading and then in the weekend and public holiday excursions of these cities' middle and working classes, the zoo, like the parks that often hosted them became places to relax, be entertained and earn respite from unnatural surroundings. This notion, that the zoo functioned to alleviate urban pressures, ran in tandem with the idea that it 
somehow also expressed the metropolitan experience. Indeed, expectation developed that any modern city worth speaking of had one; both established and emergent cities across Europe and North America constructed zoos and presented them as an essential urban phenomena.

When viewed in this way, as an icon of the metropolis, analytical attention typically falls on the complex orders of space and time that compose zoos or which they are taken to produce. According to Foucault (1986: 24), for instance, the modern zoological garden is an exemplar of a heterotopia: an actual place that is at the same time a 'counter-site' that exists 'outside of all places'. In this regard, he suggests, it shares the same quality as an urban cemetery; both sites connect to the mundane space of the city that encircles them and yet somehow also remain detached or self-contained, unusual in their ability to exhibit multiple, opposed and incompatible spaces and things within them (i.e. the metropolitan dead of all classes, districts and backgrounds buried in the same plot of ground; the creatures of the world, from different regions and habitats, caged side by side) (1986: 25). There is, Foucault argues, a certain unreality and power of inversion in the universes, and the relations between sites and spaces, that such heterotopia as zoos reflect.

In such a reading, it may be taken as no accident that regular zoo visits might coincide with the period of retirement or cessation of work. For Foucault, heterotopia can achieve a point of heightened engagement when interspersed with specific ruptures or 'slices of time'; he cites the example of what he terms the societal crisis or deviation of 'old age' (1986: 25-26). In fact ethnographers of older people in England highlight the ways in which for these subjects a sense of temporality, both 'the experience of and through time' (Degnen 2012: 56) can be 
held to be original (\& see Hazan 1996). Degnen reports how in her fieldwork with a retired community in South Yorkshire 'time came to feel differently weighted', forcing her to relearn the 'temporal inflections' assigned to everyday activities (2012: 57). In these post-retirement years, one immediate challenge older people identified was what to do with 'spans of empty time'; as well as a test, finding ways of scheduling or 'passing the time' became a major source of pleasure (2012: 60). While resisting the stereotype of older people as lost in retrospection or past-facing temporal frames, Degnen observes the importance of 'memory talk' in the negotiation of her subjects present orientations (2012: 70). Likewise, she resists the assumption that they are straightforwardly deathfocused. The retired men and women she worked with might sometimes invoke a sense of living on 'borrowed time' (2012: 66), of the urgency of time running out; however, that inflection was always mediated by the simultaneous sense of having too much time and of a sense of futures that could be engaged with.

So, in this essay, I am interested in exploring how the spatio-temporal properties of an imagined intersection between zoos and the break in time marked by retirement might play out for those older people I met living in the city. This includes an interest in the various relationships to time that visitors identify, that they either claim to initiate or feel compelled to acknowledge. Indeed, I am keen to pay particular attention to those moments when the scale or directionality of a sense of temporality appears to switch, and when one relationship replaces another. Central to this account is the ambulatory nature of the zoo visit; whenever we met, individuals would invite me to accompany them on a tour of the gardens. I have tried to replicate this movement, in time and across space of the zoo, in the ethnographic description that follows. I have also 
tried to highlight the 'capacity' of the social relationships (see Corsín Jimínez 2003: 140) that matter; for me, the regular visitors' complex relationships to time are inextricably caught up with the spatio-temporal dimensions of relationship itself, including the relationship between older person and caged animal. One might additionally list the relationship to London. In fact, I argue that the ability of visitors to position themselves in the gardens and in the city that encompasses it is either directly or indirectly connected to the capacity of social relationship that they find in both these places or which they believe these places identify in them; a complex of spatio-temporal scales perhaps best captured in the very conjunction 'London Zoo.'

\section{Species Individual:}

When we next meet, Ron directs my attention to the information plaque in front of Smokey's enclosure. Thus, I discover that he and his cage mates are not just any kind of monkey, but in fact Red-faced black spider monkeys, whose relative uniqueness in the zoo lies in their extraordinary ability to use their tail as another gripping limb. An adaptation, I read on, that makes them agile movers through the rainforest canopy of South America, their natural habitat. Equivalent plaques outside other enclosures reinforce such details. Indeed, as is customary in zoological gardens (see Baratay \& Hardouin-Fugie 2002, Lee 2005, Donahue \& Trump 2006), public encounters with captive animals at London Zoo are mediated by the language and spatial arrangement of species classification; a fact also evinced by the overall distribution of creatures on display. Individual animals or groups of animals are enclosed in spaces by species-type or sometimes by inter-species habitat, and then aggregated together with other 
related genus, subfamily, family or order species. While these classificatory juxtapositions are by no means always consistent, there remains an assumption that captive animals will index or objectify generic species qualities and that therefore those of the same species naturally belong together.

Ron does not question this principle of relationship nor the spatial organization it implies. In fact he is a keen consumer of species knowledge. As well as reading the information plaques beside the enclosures, he keeps himself updated by examining encyclopaedias and watching wildlife documentaries on the television. He also regularly stops and asks the zookeepers for more information. But most importantly, he relies on his own observations of what he identifies as species behavior. Indeed, after our initial meetings, Ron invites me to join him on one of his regular tours of the zoo. Although this circuit is never exactly the same, he explains that it does contain certain constants. First and foremost, Ron always visits his 'favourite species'. As well as the Red-faced black spider monkeys, there are the Giraffes, the Scarlet ibis, Moluccan cockatoo, Elephants, White-cheeked gibbons, Maned wolves, Black-winged lorries, Oriental small-clawed otters, Sloth bears and Red start. Begun when he first started visiting London Zoo as a means of making his time in the gardens and with the animals more manageable, the number of favourite species has slowly grown from a starting figure of ten.

However, Ron's tours are not entirely orthodox acts of classification. Alongside his observations of species behavior, he often includes reflection and anecdotal commentary on particular caged animals. Indeed, as we got to know each other, Ron revealed himself to be a far more radical non conventional classifier. His favourite species, he confides, were not merely chosen on the basis 
of species type, but also in terms of the possible relationship he felt he could have with those individual animals. Sometimes this was a relationship born out of sympathy — when Ron first saw the Red start, for instance, he felt it was lonely because there were no other birds sharing its cage- but more often it was put down to a sense of strong mutual connection. When we come to the Blackwinged lorries, for instance, he immediately starts making cooing noises and nodding eagerly for me to attend as one of the birds hops to the front of the cage and knaws on his finger. 'I like where you bond with animals,' he elaborates, 'I'm sure they get pleasure out of it, seeing me and vice versa, it's a two way thing.' Ron then chose his species to follow on the grounds that the individual animals assigned that typology seemed also to choose or display an interest in him. As he explains beside the Sloth bear enclosure, 'I have identified with these because these identify with me'. He insists that such connections are only possible because he, unlike most visitors to the zoo, sees the animals regularly and spends significant time with them. For Ron, his solitary journeys to and around the zoo take the form of paying a visit; an action that suggests forwardpropelling attachment between himself and other specific non human beings. In other words, his meetings are with species but also, sometimes, with species individuals; the spatial and temporal capacities of the latter relationship have a quite distinct directionality. Indeed, it is possible to read Ron's assertion of mutual identification with certain zoo animals as an analogue to the claim for interspecies encounter at the scale of what Haraway terms 'personal' or 'face-toface' time (2003: 63); that is, as an exchange between fleshy bodies and perspectives and the individual lifetimes that each contains. For Haraway, the value of such a distinction lies precisely in foregrounding an alternative scale to 
human-animal relations, or at least placing it side-by-side with more dominant scales of interspecies temporal relationship such as evolutionary time (a key scale of zoological species knowledge). Certainly the cross-species interdependence between individuals implied by the evocation of face-to-face time_for Haraway this is crucially a relationship between two knowing subjects — is something that would chime with the emphasis placed by Ron.

This includes a sense of some of these animals as themselves autonomous observers in the zoological garden. 'What I enjoy about Smokey,' he once explained, 'is that he's supposed to be in captivity, which he is, but he's using the public to get his amusement. I love that.' For Ron, this is best demonstrated by what Smokey's keeper regards as the monkey's transgressive behavior. As well as dancing and gesticulating in front of selected visitors and following them around the enclosure, he tells me that Smokey is well known for having a 'fancy' and becoming sexually aroused in the presence of men, especially those with marked facial hair. The most excited Smokey ever became, Ron leans over to inform me, was when a group of Hasidic Jews from Stamford Hill visited the zoo. In fact Ron revels in the idea that these captive animals have their own point of view, may themselves be watching subjects or classifiers of the humans that visit them. Part of the attachment Ron expresses for particular species individuals then lies in the exterior perspective they offer him of his fellow humanity; he feels like he shares or is 'in-on' what he takes to be Smokey's joke.

In his mind, this insider perspective differentiates him again from other, less regular zoo visitors but also to a certain extent from the staff and institution of the zoological gardens. 'I'm rather eccentric,' he tells me, 'because when I look at the animals I just treat them as an equal. I mean I don't try and analyse them, 
the relation is instinctive.' Such statements are often a cue for him to launch into one of his most common complaints about the zoo, the fact that the information plaques beside the enclosures never state the names of the individual creatures (Ron only knows the names because he has overheard keepers using them). For him, the absence is a denial of species individuality. Indeed, his passion on this topic drives Ron to make a point of going round and telling other zoo visitors, like myself, the names of the animals we are looking at.

The significance of this action must also be seen in the light of Ron's views about his fellow Londoners. As a self-professed 'loner', someone who feels continually disappointed or let down by urban humanity, seeking out contact in this fashion is not obvious. In fact there is a sense in which the exterior observations on humanity offered to him by sharing the joke with Smokey already duplicates an existing outsider perspective. The long hours spent with his favoured captive animals consistently reinforce reflections on the limits of his own species. Beside the Giant anteaters, for instance, Ron tells me that he likes animals better than humans. 'They're more reliable,' he elaborates, 'provided you treat them well they respond with love.' The reverse, he insists, is the case with people: 'I mean you treat someone really kindly and suddenly they do the dirty on you, there's no accounting for the way humans react.' This lack of trust in the city is precisely what for him makes zoo visits such a pleasure. 'I feel more at peace here than I would standing about on the Tube or working in an office,' he explains, 'with humans there's so much complications, people always trying to be clever, but there's nothing false about these animals, they're just themselves.' By extension, Ron feels that their recognition of his presence allows him to be himself, alone but at ease in his detachment from the company of Londoners. So 
the kind of personal Ron and Smokey time he evokes at the zoo is not just equivalent to that between human individuals he knows or encounters in the city; it is actually an improvement or refinement of those relations and an on going basis for critique.

In fact the very notion of 'old age' and the cessation of work as a slice of time that unites and makes sense of the experience of the regular zoo visitors I knew is also compromised by the example Ron provides. As he continually emphasizes, his retirement is not so much an abrupt break with the temporal orientation of working life as it is the fulfilment of his ambition to be left alone. Indeed, he speaks of a career organized to plan, one whose goal is to evacuate the context of human company, or rather to make Ron the context or scale of his own life. As a loner, he explains, he has always liked to do his 'own thing' and 'not to be bossed around'. Hence he chose to become a bookmaker, working at various London dog tracks, and from a young age determined to work and save towards an early retirement and the goal of a self-authored life completely dedicated to his driving passions (i.e. watching cricket, attending London theatre and betting at the horse races). And indeed some twenty years ago, at the age of forty-eight, Ron achieved his dream. As well as regularly visiting the zoo, a passion that only emerged after his retirement, he now devotes his time to this plan of selfentertainment; regularly going to matiness performances in the West End, visiting the all-weather track at Lingfield and in the summer months spending long days at the Oval. While the nature of this routine can sound much like the practice of making 'weekly schedules' that Degnen (2012: 58) describes older people in South Yorkshire investing in in order to meet the challenge of marking and passing too much time, the equivalence is not convincing. For although Ron 
can speak like the other regular zoo visitors I knew of living a life in retirement, there is a strong sense in which he feels he has reached his desired future, at least the conclusion he once planned for himself (his routine is not a response to the empty time of retirement but rather an actualization of the ambitions that motivated the temporal inflection of his working life). Ron insists that beyond these entertainments he has no ambitions or designs for human interaction, little or no investment in the city he inhabits. In his case, hope for any genuinely interdependent relationship is entirely displaced or reoriented to encounters with Smokey and other zoo animals.

The extent to which attachment to human personal relationships or faceto-face time has ended was best epitomized for Ron by recent news of an unexpected 'windfall.' Standing beside the giraffe enclosure one day, he informs me that he has just received notification of substantial monies from the inheritance of a previously unknown relative. The deceased, he learnt, was his great great aunt or mother's cousin, who died at the age of one hundred and one in Finchley, a neighbouring suburb in his own London borough. As Ron tells me the story he shrugs his shoulders dismissively and says it is 'just typical, like when you wait for a bus for ages and then three come at the same time' (a classic complaint of the London commuter). When he was younger, Ron explains, he could have benefitted from such an unanticipated legacy; it might have really made a difference when he was still driven by the indeterminacy of his dream of early retirement or at a time when his life with other humans was still unfolding. But now the windfall is completely meaningless; for his finances are all worked out and he has everything he requires (i.e. his retirement plan is fully realized). Although, Ron claims, he is not religious, such surprises make him feel that there 
must be some kind of 'Outer Force' at play in the world, an energy or power that gives one the opposite of what one needs. 'How else,' he laughs, 'can one explain evolution!'

The aside is funny, but also gives Ron pause for thought. Indeed, it is a reference that quite suddenly alters the tone of his reflections. Having introduced the idiom of common descent without much thought, he begins to connect up on a very different basis with the lives of the captive animals we go on to visit. Our perceived ties may be temporally more distant or close_at the spider monkey enclosure, Ron tells me that he 'can quite believe we actually came from this species'__ but as he highlights linear evolution means we are all part of something that historically shapes and embraces us and explains why we are here. From this vertical perspective, everything connects and spreads downwards through the reproduction of life across generations (a principle of non-recursive or progressive genealogical time, which Franklin [2000: 218] claims, animates its 'ontological constitution as a force'), a relationship whose temporal capacity not only redirects a sense of momentum, but also obviates the power or scale of Ron in the city and the forward-pressing personal attachments with his favourite zoo animals.

The context of this aside also hints at the capacity of human relationship in the city to be re-spatialised. However much he may resist an interpretation of his windfall as an opportunity to identify relations or reconnect with his fellow Londoners_ — he tells me, for instance, that he has no interest in visiting the home of his previously unknown benefactor or in meeting the other distant relatives who also received some inheritance_- Ron cannot fully deny the power of kinship to reveal hidden connections across the metropolis. Likewise, 
the revelation or evocation of common descent between species invites lateral renderings in space. As Ron acknowledges, and the layout of the zoological garden reminds him, zoo visits are also a way of viewing related species side by side and assessing spatially the hidden temporal connections implicated in their shared origins.

\section{Web of life:}

Half way through one of our walks, we bump into Audrey, who Ron introduces as another regular zoo visitor. A bespectacled woman that looks to be in her early seventies, she smiles nicely through bright red, unevenly applied lipstick and reveals a couple of broken teeth. Audrey stops long enough to explain that like Ron she has been coming to London Zoo for many years; hopping on the Victoria Line twice a week to make the hour long journey from her home in Chingford, on the outskirts of the city, down to the nearest tube station and then onto a bus. I manage to make a hurried arrangement to rendezvous on another day and then she is off, disarmingly sprightly in a flowery summer dress.

When we do meet again, Audrey suggests we 'walk and talk', taking her normal route around the zoo. Like Ron's tours, this involves a visit to some of her favourite animals; she too likes the Sloth bears and the Giraffes, however also takes me to see the Malayan tapir, Fruit bats, Bearded pigs and the Arabian gazelle. More distinctively, Audrey leads me to the large exhibition hall known as the Web of Life. Built in 1999 as a millennium project to house a display on biodiversity, the building had just won a number of awards for the innovative way it illustrate these themes through exhibits of living animals, particularly invertebrates, and for its efficient conservation-friendly design. As Audrey's 
commentary emphasizes, the focus here is on a slightly different spatio-temporal scale of relationship: the interdependence of species through habitat reliance.

One of the first exhibits we encounter contains a series of boxes, linked by ropes, hung to allow a colony of Leaf-cutter ants to move between their nest and food supply. As I watch them carry pieces of leaf many times their own size across the ropes, Audrey, reading from the information plaque, tells me that the insects live in tropical rainforest and that they perform a crucial role in sustaining the local environment. 'Isn't it amazing,' she says, 'its what they call the eco-system, you can't have one part without the other.' Passing between a cabinet of Giant orb spiders in their web, tanks of sea horses and Upside-down jellyfish, she then leads me to a display bowl of Blue-fly larvae. 'If you're murdered,' Audrey informs me with relish, 'the pathologist can tell how long you have been buried by examining their life cycle, and also whether your body has been moved.' Once again the lesson is that everything is interconnected in specific environments.

For Audrey, this is perhaps most thrillingly illustrated through examples of 'adaptation'. Time and again, both inside the exhibition hall and outside during our visits to animal enclosures, the evidence provided of specialized habitat development impresses her. Standing in front of the Arabian Oryx, for instance, Audrey explains that these strikingly white antelope are actually born brown.

The simple reason is that they live in the desert and the sand is brown, so its camouflage, and then they turn white as they get older to help reflect the heat. Well that's Nature isn't it. Wherever an animal is, wherever it is born, it adapts to the temperature. It's like a polar bear. I mean all the fur 
on the polar bear is insulated, its feet too so it can walk on ice and snow. Animals adapt whatever particular area of the world they live in.

The emphasis is repeated because Audrey believes the issue of adaptability is what crucially distinguishes humans from other animals. Civilization, she states, means humans no longer have to adapt; they do not need fur, for instance, because they have clothes and houses to keep them warm. Seen from this perspective, urbanization is the apex of the civilization process; a city like London is a piece of technology that makes human adaptation to place appear more and more unnecessary. As a result, Audrey highlights, people think they can detach themselves from local environment and live without sympathy for its other species.

Despite these strong concerns for biodiversity and the preservation of species rich habitats, Audrey tells me she remains unconvinced by the claims of evolutionists. For her, the spatial interdependence of species and their mutual adaptation to local environments does not necessarily suggest a kinship between them over time. In this regard, she radically differs from Ron. Indeed, while he finds that the manners and expression of certain animals at the zoo, such as the spider monkeys, powerfully indicates a shared genealogy or common descent between human and non human animals, Audrey finds the exact reverse. To her the presence of these creatures demonstrates the fact that species are essentially different and unique. 'I don't know, evolution doesn't seem right to me somehow,' she expands as we watch the Chimpanzees, 'for when you look at any species of animal its miraculous the way it is made.' In response to my questioning, Audrey insists this position is not a 'religious thing', but rather an outcome of her reasoning and simple observations. 'I mean if we have evolved 
why haven't they [the Chimpanzees],' she continues, 'and why is it that we've got so many different people with different coloured skin and different features.'

This train of thought leads Audrey to the example of birds: 'And another factor is, you will never get birds inbreeding, I mean you will never get a sparrow mating with a blackbird, they all keep to their own species.' Such 'amazing coincidences', she holds, only further problematize the notion that species evolve from each other.

As already explored, one explanation for species difference is adaptation, a process that for Audrey seems to occur outside linear evolutionary time. So the Arabian Oryx is brown at birth because that is the colour of the desert; equally it turns white because that is the habitat response to extreme heat. For her, none of this suggests the animal might once have been something else (i.e. descended from another species). It does not even really suggest the idea of 'co-evolution' (see Haraway 2003), the mutual shaping of species over time in specific habitats. Instead, for her the Oryx seems to have come into existence in situ. Indeed, there is a strong mimetic quality to her theory of adaptation. Species are quite literally expressions of their environments or natural place.

The assumption is important because it keeps playing into her observations of London. While at one level the city is an exemplification of the universal human cultural capacity to escape the requirements of adaptation—in this regard, Londoners are not like the Oryx; there is a diminishing mimesis between people and place_-in other moments she seems to suggest that some humans are more adapted than others. Perhaps unsurprisingly, taking on board her aside on avian inbreeding and her theory of atemporal adaptation, Audrey expresses concerns about the levels of 
immigration. At the Web of Life exhibition, for instance, she digresses from our conversations on habitat reliance in order to relay a story she read in the newspaper that morning about an incident in a city mall where two gangs of Kosovo asylum seekers set upon each other and fought with knives. The anecdote is presented as evidence of non adapted behaviour - this is not how Londoners behave — but also of a lack of care in the city. London is not what it used to be, Audrey tells me, because it is 'too crowded, there are too many people here, I mean you won't be able to move soon, can't move now.' It is in other words an environment in crisis. Indeed, Audrey connects the overcrowding due to immigration with what she perceives as the increasing physical degradation of the metropolis. 'I live in a filthy, dirty city,' she informs me, 'because nobody cares do they, they just throw everything on the road.' These comments suggest that unlike Ron, who has no investment or hope in urban human futures_as long as the city leaves him alone to pursue his passions he is content_-Audrey is deeply concerned to envisage an alternative city. Drawing upon the spatial capacity of the trope of biodiversity, she longs to see a re-balanced metropolis, once again home to a sustainably reduced and fully adapted native human population.

But Audrey is also aware of the irony of presenting zoo animals as examples of habitat reliant, naturally adapted species. As both she and Ron regularly point out, these creatures are largely born in captivity, not in the wild, and are often the offspring of previous generations of captive animals. They are then, much like the London immigrants that Audrey bemoans, crucially out of context, cut off from the environments to which they are meant to be mimetically adapted. Not only that, the animals are constantly on the move, with individuals 
regularly transported between zoos in order to meet the requirements of species breeding programmes or the changing demands of the public (Smokey, for instance, originally came to Regents Park from a zoo in South Devon, and one of his cage mates came from Amsterdam; the Maned wolves arrived from Edinburgh Zoo). Like the city, the zoological garden is therefore a site of unstable population and intersection; many of its caged creatures are also technically visitors. While Audrey resists this particular analogy, she, like Ron, admits to feeling sometimes disturbed by the prospect that certain zoo animals might be relocated.

The loss of species and species individuals to other zoos might be unsettling for their regular human visitors, but it is especially distressing, Audrey holds, for the creatures involved. As well as feeling the absence of their cohabiting group keenly, these departed animals will miss the personal ties to known humans such as their keepers and those members of the public who pay them visits. But her concern for the wellbeing of transported animals is matched by a concern for the well being of those creatures that arrive or remain at the zoo. This is because in her estimation the numbers of older people who are regular visitors is also clearly declining. Sitting on a park bench eating her packed lunch after our walk, Audrey tells me that at times she feels like one of the last survivors.

There was a lady who'd come for the last thirty years, but she died at Christmas, one of the gibbons was really attached to her. Then there's Jim and Mary. Well unfortunately Jim had to go into hospital, and she hasn't been here since. And quite a few others have died you know, because they are quite elderly. 
For Audrey, the sense of the group's demise, including the reinforcement of the awareness that they are all living on 'borrowed time' (see Degnen 2012: 66), connects to a wider awareness of life's passing. She is very conscious of the zoo's role in preserving animals from annihilation, of the estimated extinction time of various 'endangered' species exhibited or displayed at the Web of Life. Indeed, as she often highlights, the range of living things is constantly diminishing. 'Look at the example of the Dodo or the Caspian Tiger,' she observes, 'I mean in there it says there used to be four hundred million Carrier pigeons, but we shot them all.' As she warns, 'eventually we'll be taken too.' Despite her rejection of linear evolution, there is then a negative faith in the temporal inclusivity of future mutual inter-species dying out. If the force or 'animate vitality' of genealogical time brought species into connection through the forward-pressing motor of descent (Franklin 2000: 218), the ontological constitution of extinction promises connection through a staggered but ultimately embracive end of life (see Chrulew 2011). In the survival stakes, Audrey believes that humans will prove unexceptional; as she points out before we say goodbye, the only creatures left when everything else is 'snuffed out' will be the ants.

\section{Conclusion:}

Reflection on the declining number of regular zoo visitors brings Audrey back to the zoological garden itself as a temporalized or historical space. For, as she frequently highlights, London Zoo has been under threat of closure for many years, intermittently forced to face the real prospect of its own demise. Most recently and dramatically in 1991, when the Council of the Zoological Society of London publicly announced it's near-bankruptcy, a situation only saved by the 
philanthropic intervention of some wealthy patrons and the later commitment of the newly elected London Mayor (acting, so he claimed, in the interests of the city). These concerns about the economic future of the zoo continue to generate anxiety and to spark response. Ron, for instance, told me that he has already given small donations and that he plans to make the zoological garden the major beneficiary of a legacy, now boosted by his windfall (the outcome of a hidden relationship that for him now has purpose). Audrey, like many of the other regular visitors, is an enthusiastic sponsor of the 'adopt an animal' scheme. All of them express the hope that a sustainable financial future will emerge, and that through their donations and sponsorship they can make a contribution that might outlast individual futures or the time as active subjects that each has left.

However, perhaps even more pressing is the fear that time may be up on the very idea of the zoo, including the notion that it is an appropriate space in the city. These visitors are not unaware, for example, of the critiques from animal rights campaigners, who occasionally sprawl anti-zoo graffiti on enclosure walls. This sense of entering a space that could be at the end of its time reminds them that they occupy a city in which they too may appear increasingly anachronistic or out of synchrony with urban times. An invitation to rethink the zoological garden negatively__ for instance, as a dystopian kind of place, which reflects not an escape into Nature or the Wild, but a hyper intensification of metropolitan denaturalization—makes them feel that perhaps it is best to be on the way out. Indeed, once embraced, this pessimistic vision can draw out new kinds of sympathy between visitor and gardens. If the zoo is really just waiting for its gates to be closed, also living on borrowed time, then why not wait together. 


\section{Acknowledgements:}

Of course I would like to thank those visitors to the zoo I worked with. My special thanks to Morten Nielsen for inviting me to contribute to this special issue. I am also grateful for the comments and feedback of Matei Candea, Alberto Corsin Jimenez, Shari Sabeti and Tom Yarrow. A version of this paper was given at the anthropology department seminar series at UCL and I thank those audiences too.

\section{References:}

Baratay, Eric \& Elisabeth Hardouin-Fugie. 2002. Zoo: a history of zoological Gardens in the West. London: Reaktion Books.

Barrington-Johnson, J. 2005. The Zoo: the Story of London Zoo. London: Robert Hale.

Chrulew, Matthew. 2011. 'Managing love and Death at the Zoo: the Biopolitics of Endangered Species Preservation'. Australian Humanities Review 50: 137-157. Corsín Jimínez, Alberto. 2003. 'On Space as a Capacity'. Journal of the Royal Anthropological Institute 9: 137-153.

Degnen, Cathrine. 2012. Ageing Selves and Everyday Life in the North of England: Years in the Making. Manchester: Manchester University Press.

Donahue, Jesse \& Erik Trump. 2006. The Politics of Zoos: exotic animals and their protectors. DeKalb: Northern Illinois University Press.

Foucault, Michel.1986. 'Of Other Spaces'. Diacritics 16: 22-27. Franklin, Sarah. 2000. 'Life Itself: Global Nature and the Genetic Imaginary'. In Global Nature, Global Culture. Sarah Franklin, Celia Lury \& Jackie Stacey, eds. Pp: 188-227. London: Sage. 
Haraway, Donna. 1991. Simians, Cyborgs, and Women: the reinvention of Nature. New York: Routledge.

--. 2003. The Companion Species Manifesto: Dogs, People, and Significant Otherness. Prickly Paradigm Press.

--. 2007. When Species Meet. Minnesota: University of Minnesota Press.

Hazan, Haim. 1996. From First Principles: an Experiment in Ageing. London:

Bergin \& Garvey.

Lee, Keekok. 2005. Zoos: a Philosophical Tour. Basingstoke: Palgrave Macmillan. Mullan, Bob \& Garry Marvin. 1987. Zoo Culture. London: Weidenfeld \& Nicolson. Rothfels, Nigel. 2008. 'Savages and Beasts: the Birth of the Modern Zoo (Animals, History, Culture)'. Baltimore: The John Hopkins University Press. 